Abstracta Iranica Abstracta Iranica

Revue bibliographique pour le domaine irano-aryen

Volume 42-43 | 2021

Comptes rendus des publications de 2019-2020

\title{
Denis Hermann, Mathieu Terrier (eds.). Shi'i Islam and Sufism. Classical Views and Moden Perspectives
}

\section{Denise Aigle}

\section{OpenEdition}

1 Journals

\section{Édition électronique}

URL : https://journals.openedition.org/abstractairanica/54304

DOI : 10.4000/abstractairanica.54304

ISSN : 1961-960X

Éditeur :

CNRS (UMR 7528 Mondes iraniens et indiens), Éditions de l'IFRI

Référence électronique

Denise Aigle, "Denis Hermann, Mathieu Terrier (eds.). Shii Islam and Sufism. Classical Views and Moden Perspectives », Abstracta Iranica [En ligne], Volume 42-43 | 2021, document 2, mis en ligne le 30 décembre 2021, consulté le 13 décembre 2022. URL : http://journals.openedition.org/ abstractairanica/54304; DOI : https://doi.org/10.4000/abstractairanica.54304

Ce document a été généré automatiquement le 13 décembre 2022.

Tous droits réservés 


\title{
Denis Hermann, Mathieu Terrier (eds.). Shi'i Islam and Sufism. Classical Views and Moden Perspectives
}

\author{
Denise Aigle
}

\section{RÉFÉRENCE}

Denis Hermann, Mathieu Terrier (eds.). Shi'i Islam and Sufism. Classical Views and Moden

Perspectives. Londres: I.B. Tauris \& The Institute of Ismaili Studies, 2020.

1 Cet ouvrage ouvre de nouvelles perspectives sur les relations entre le chiisme et le soufisme en Iran, en Anatolie et en Inde à partir de la période safavide. Alors qu'on a souvent considéré qu'il existait une rivalité entre les chiites et les soufis, les études regroupées dans cet ouvrage remettent en question cette opposition.

2 Les éditeurs, D. Hermann et M. Terrier, expliquent dans l'introduction que les chercheurs ont affirmé que la dimension mystique de l'islam ne s'incarnait que dans le soufisme sunnite tandis que les doctrines chiites étaient considérées comme hétérodoxes. Néanmoins, disent-ils, il devient difficile d'établir la distinction entre certaines notions communes. Ils prennent l'exemple de la walāya. Dans le chiisme et appliquée à l'imam, la walāya désigne le "saint pouvoir ", l'« autorité », appliquée aux fidèles, elle désigne l'amour (mahabba), la foi et la soumission au guide initiatique. Alors que dans le soufisme, la walāya désigne la sainteté, la proximité avec Dieu. On fait la même constatation à propos du quțb, le pôle, l'axe de la création du soufisme, et l'imam du chiisme. Les liens entre soufisme et chiisme ont été ignorés par les spécialistes du soufisme les conduisant à de mauvaises interprétations comme par exemple John Spencer Trimingham qui, dans son ouvrage sur les ordres soufis (The Soufi Orders in Islam, 1971), affirme qu'ils n'ont jamais engendré des tendances sectaires. Cette position a radicalement changé avec les recherches de Henry Corbin, en particulier dans L'imagination créatrice dans le soufisme d'Ibn 'Arabî publié en 1958, mais il n'a pas prêté 
attention aux aspects historico-sociaux du soufisme. D. Hermann et M. Terrier rendent hommage aux chercheurs qui ont ouvert la voix aux études sur les liens entre soufisme et chiisme. Le chercheur irakien, Kāmil Mușțafā al-Shaybī, est l'auteur d'un ouvrage pionnier: al-Ṣila baynal tașawwwūf wal-tashayyu ("Les liens entre soufisme et chiisme») publié à Bagdad en 1953. Il est resté ignoré des chercheurs occidentaux jusqu'à sa traduction en anglais en 1991.

3 Les articles ont été regroupés en trois parties. La première "Alternative to anti-sufi discourse in pre-modern and modern Shi'i literature" s'intéresse au discours des ulam $\vec{a}$ ' chiite sur le soufisme. La deuxième "The social history of a Shi'i sufi brotherhood: the Ni'mat Allāhiyya » est consacrée à l'histoire intellectuelle et sociale de l'un des ordres soufis les plus importants d'Iran. La troisième "Relations between Shi'ism and Sufism in other sufi literary traditions " s'intéresse aux relations entre chiisme et soufisme dans des traditions textuelles jusqu'ici peu exploitées des Alevis, des Bektashis et des Khāksāriyya.

4 Cet ouvrage collectif réexamine les relations entre chiisme et soufisme en combinant différentes approches : philosophie, sciences des religions, histoire sociale, artistique et politique, anthropologie. Par ailleurs, les auteurs utilisent des sources peu exploitées ainsi que des traditions orales. Cette approche pluridisciplinaire, de surcroît sur une vaste aire géographique, fait de cet ouvrage un pionnier dans le domaine des études sur le chiisme et le soufisme.

\section{AUTEURS}

DENISE AIGLE

UMR 8167 - Orient et Méditerranée 